\title{
Dark Triad Personalities, Self-control, and Antisocial/ Criminal Outcomes in Youth
}

\author{
Pedro Pechorro PhD (iD ${ }^{a}$, Matt DeLisi PhD ${ }^{b}$, Rui Abrunhosa Gonçalves PhD, \\ Teresa Braga $\mathrm{PhD}^{\mathrm{a}}$, and João Maroco PhD (iD ${ }^{c}$

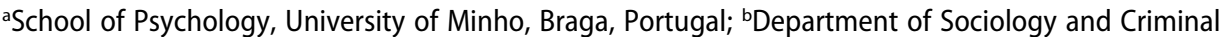 \\ Justice, lowa State University, Ames, lowa, USA; 'William James Centre for Research, ISPA-Instituto \\ Universitário, Lisboa, Portugal
}

\begin{abstract}
The Dark Triad composed of psychopathy, Machiavellianism, and narcissism, and also self-control are consistently related to antisocial and criminal externalizing outcomes. In the present study, we examined whether self-control mediates the relationships between the Dark Triad and delinquency, conduct disorder, and crime seriousness outcomes. The sample consisted of 567 adolescents $(M=15.91$ years, $S D=0.99$ years, range $=14-$ 18 years) from Portugal. Self-control mediated the association between psychopathy and Machiavellianism (but not narcissism) and self-reported juvenile delinquency, conduct disorder symptoms, and crime seriousness. One reason antisocial/criminal behaviors are common in those characterized by psychopathy and Machiavellianism relates to their deficits in selfcontrol as suggested by general theories. Within the nomological network of dark traits, narcissism appears to have enduring and unmediated associations with externalizing features and conduct problems. Our findings add to the literature modeling the Dark Triad along with self-control to elucidate its contributions to antisocial/criminal outcomes in youth.
\end{abstract}

\section{KEYWORDS}

Conduct disorder; Dark Triad; juvenile delinquency; selfcontrol; youth

\section{Introduction}

Research in developmental psychopathology, personality psychology, and criminology consistently points to the salience of dark personality features and their association with diverse conduct problems. Within this nomological network, two of the most studied constructs are self-control (e.g., Gottfredson \& Hirschi, 1990) and the Dark Triad that includes narcissism, Machiavellianism, and psychopathy (e.g., Paulhus \& Williams, 2002). Narcissism is characterized by selfishness, self-centeredness, entitlement, low empathy, and need for admiration from others. Machiavellianism is defined as a person who is cunning, scheming, and unscrupulous in their behavior and who exploits others toward self-serving goals. Psychopathy is consistent with Antisocial Personality Disorder and describes a person who has self-regulation

CONTACT Pedro Pechorro ppechorro@gmail.com E University of Minho, Campus de Gualtar, Braga 4710-057, Portugal 
problems, low empathy, reduced emotional connections to others, is impulsive, and engages in a range of imprudent behaviors many of which are criminal. Although these are theorized as distinct constructs and have independent research literatures, they collectively embody an individual who has poor emotional and behavioral regulation, who is self-centered and pursues self-interest with disregard for others, who has a duplicitous and manipulative interpersonal style, or who is prone to conduct problems and correlated imprudent behaviors. Although psychopathy and narcissism have more explicit connections to self-regulation deficits, all of the Dark Triad features including Machiavellianism share a sense of ruthlessness in the pursuit of selfinterest. To date, several meta-analytic studies indicate that the Dark Triad (Muris et al., 2017; O’Boyle et al., 2015; Schreiber \& Marcus, 2020; Vize et al., 2018) and self-control (De Ridder et al., 2012; Pratt et al., 2014; Vazsonyi et al., 2017; Walters, 2016) are significantly related to assorted antisocial outcomes (e.g., aggression, victimization, violent, property, or substance offending) and/ or personality pathology.

Although self-control and the Dark Triad are consistently associated with antisocial outcomes, less research has jointly examined these constructs in the same study. To illustrate, Miller et al. (2019) found that only $5 \%$ of studies jointly examined the correlations among psychopathy, narcissism, and Machiavellianism and behavioral outcomes, most of which did not include self-control. Among studies that examined the Dark Triad and self-control and their correlations to antisocial conduct, the results are varied. In two studies using university students as participants, Jonason and Tost (2010) reported significant evidence of the interrelationship between self-control and the Dark Triad. In study 1, selfcontrol significantly correlated with a composite Dark Triad measure, psychopathy, and narcissism, but not Machiavellianism. Consideration of future consequence and ADHD symptoms significantly correlated with the composite Dark Triad measure and psychopathy, but not narcissism or Machiavellianism. In study 2, self-control, consideration of future consequences, and ADHD symptoms correlated with the composite and constitutive Dark Triad measures with the exception of a null correlation between future consequences and narcissism.

Drawing on nationally representative data from the National Epidemiological Study on Alcohol and Related Conditions (NESARC), Larson et al. (2015) performed latent class analysis and identified four classes characterized by differential levels of narcissism and self-control. Whereas nearly $60 \%$ of the participants had low narcissism and high self-control and thus exhibited normative personality functioning, Larson et al. also identified a class with high narcissism and low self-control that constituted $6.4 \%$ of the sample. This small class had the most severe sociodemographic, psychiatric, and substance abuse risk profile and were elevated risk for all forms of violent 
behavior. Forms of violence included four forms of intimate partner violence, bullying, cruelty to animals, sexual assault, robbery, assault with weapon, and assault. Although not directly about the Dark Triad, their study nevertheless showed the salience of narcissism and self-control deficits for understanding variance in conduct problems and violence (also see, Mowlaie et al., 2016; Vaughn et al., 2007, 2008; Walters, 2019).

Another study using data from nearly 400 adult university students (Flexon et al., 2016) found that self-control and the Dark Triad significantly correlated, but have disparate influences on various externalizing outcomes. Low self-control was significantly associated with self-reported substance use and self-reported offending, but not victimization whereas the Dark Triad was significantly associated with victimization and selfreported offending, but not self-reported substance use. Other studies similarly found that self-control and the Dark Triad have differential associations with diverse forms of antisocial conduct and crime (e.g., Lyons \& Jonason, 2015; Miller et al., 2017; Wright et al., 2017), thus it is unclear how they interrelate and whether mediation exists between these constructs and antisocial behavior.

\section{Current focus}

The Dark Triad poses an empirical puzzle for understanding how its features and self-regulation relate to conduct problems. In general, criminological theoretical models (e.g., Gottfredson \& Hirschi, 1990), self-control is a gestalt that encompasses the aversive features inherent to the Dark Triad and the components of the Dark Triad individually and collectively share a personality profile that is antagonistic and generally disagreeable (Trahair et al., 2020; Vize et al., 2020, 2019). However, some research indicates that Dark Triad features relate to other constructs, such as ambition (Truhan et al., 2021) and dispositional greed (Sekhar et al., 2020) that theoretically would typify persons with higher self-control. Moreover, although selfcontrol and the Dark Triad are clearly interrelated, prior research has mostly utilized a regression-based analytical approach that is less clear in terms of how these constructs relate, specifically whether self-control mediates associations between Dark Triad features and antisocial outcomes. In the present exploratory study, we investigate whether self-control mediates the relationships between the Dark Triad and various conduct disorders in a sample of Portuguese youths. In so doing, we concurrently examine the Dark Triad linkages to both self-control and criminality as well as linkages between self-control and antisocial outcomes. We extend previous research by examining these in a sample of youths from Portugal and test a mediation model of accounting for the links between the Dark Triad and antisociality. 


\section{Method}

\section{Participants}

Our sample consisted of 567 youth $(M=15.91$ years, $S D=0.99$ years, age range $=14-18$ years $)$, with 256 females $(M=15.80$ years, $S D=1.02$, range $=$ $14-18)$ and 311 males $(M=15.99$ years, $S D=.96$, range $=14-18)$. Genders did not differ in terms of age $(F=3.38, p=.06)$, socioeconomic status $(U=38318.50, p=.41)$, or education $(F=0.63, p=.42)$. Most of the participants were Portuguese nationals (88.4\%) with approximately 9 years of education on average $(M=8.95, S D=.94)$.

\section{Measures}

\section{Predictors}

Dirty Dozen Dark Triad (DD; Jonason \& Webster, 2010). It is composed of 12 items (four for each trait) measuring individual differences in Machiavellianism (e.g., "I have used deceit or lied to get my way"), psychopathy (e.g., "I tend to be unconcerned with the morality of my actions"), and narcissism (e.g., "I tend to seek prestige or status"). We used the Portuguese translation (Pechorro, Jonason et al., 2021). This Portuguese version of the DD was previously validated among a at-risk sample of youth and demonstrated adequate validity and reliability results. CFA confirmed the presence of the three factors, which showed marginal to adequate internal consistency values (a range .54-.74). Participants were asked their agreement (1 = Strongly Disagree; 5 = Strongly Agree $)$ with each item. For the current study, the items of each trait were summed to create indexes of Machiavellianism (Cronbach's $\alpha=.86)$, psychopathy $(\alpha=.93)$, and narcis$\operatorname{sism}(\alpha=.88)$.

\section{Mediator}

Brief Self-Control Scale (BSCS; Tangney et al., 2004). It is composed of 13 items measuring individual differences in self-control (e.g., "I refuse things that are bad for me," "I am able to work effectively toward long-term goals"). The Portuguese translation was used in the current study (Pechorro, DeLisi et al., 2021). This Portuguese version of the BSCS was previously validated among incarcerated and community youth and demonstrated adequate validity and reliability results. CFA confirmed the presence of a single factor, which showed adequate to good internal consistency values ( $\alpha$ range .75-.94). Participants were asked their agreement $(1=$ Not at all like me; $5=$ Very much like me $)$ with each item. Items were reverse-scored so higher scores reflect lower levels of self-control. For the current study, the items were summed to create an index of self-control $(\alpha=.93)$. 


\section{Outcomes}

Add Health Self-Report Delinquency (AHSRD; Pechorro, Moreira et al., 2019) scale. It is composed of 17 items measuring individual differences in terms of delinquent behaviors (e.g., "Take something from a store without paying for it," "Steal something worth less than €50"). The AHSRD was previously validated among at-risk for delinquency Portuguese youth and demonstrated adequate validity and reliability results. CFA confirmed that a single factor solution obtained a good fit with good internal consistency $(\alpha=.90)$. Participants were asked the frequency of their delinquent behaviors occurring during the last year $(0=$ None; $3=$ Five or more times $)$ with each item. For the current study, the items were summed to create an index of self-reported delinquency $(\alpha=.93)$,

Conduct Disorder Screener (CDS; Lewinsohn et al., 2000). It is composed of six items measuring individual differences in conduct disorder behaviors (e.g., "I got into fights," "I skipped school," "I got into trouble for lying or stealing"). The Portuguese translation was used in the current study (Palma et al., in press). This Portuguese version of the CDS was previously validated among incarcerated and community youth and demonstrated adequate validity and reliability results. CFA confirmed the presence of a single factor, which showed adequate to good internal consistency values ( $\alpha$ range .75-.88). Participants were asked the frequency of their behaviors $(1=$ Rarely or none of the time, $4=$ Most or all of the time) with each item. For the current study, the items were summed to create an index of conduct disorder $(\alpha=.84)$.

We also used a Portuguese version of the Delinquency Seriousness Classification Index (DSCI) originally developed by Loeber et al. (1998) to classify crime seriousness. It employs a four-level progressive ordinal sequence, with higher scores indicating higher seriousness levels of crimes committed by youth.

\section{Procedures}

The ethics committee of the Ministry of Education of the Portuguese State provided authorization to assess the participants of the present study. These participants came from state-managed public schools in southern Portugal, including the capital city Lisbon, Alentejo and Algarve. Written parental authorization was previously obtained, and then the potential participants were themselves informed about the aims of our investigation and asked to collaborate voluntarily (Declaration of Helsinki principles were followed). Due to various reasons, some youth were excluded (i.e., those who could not read/understand Portuguese, those who were reluctant to participate, those who were 13 or younger to ensure the reading 
level was generally appropriate to the item content of the measures used, and those who were 19 years old or older because they are considered young adults). The rate of participation was $89 \%$. No form of compensation was given to the participants or their parents. The sociodemographic questionnaire and measures included in the present study were administered in small groups of participants.

\section{Data analysis}

EQS 6.4 (Bentler \& Wu, 2018) software was used to examine descriptive statistics, Pearson correlations, group differences, reliability of the measures, and estimate models (that is, to analyze the direct and indirect effects between the Dark Triad traits and the several outcomes). We tested three specific models. In Model 1, the Dark Triad impacted self-reported delinquency directly and indirectly via their influence on self-control. In Model 2 , the traits impacted individual differences in conduct disorders directly and indirectly via their influence on self-control. In Model 3, the traits impacted crime seriousness directly and indirectly via their influence on self-control. The four items per measure with the highest loadings were selected to build the latent measurement models, and no modification indices were used to improve these models. Maximum Likelihood Robust (MLR) methods with covariance matrices were used; these methods work well when distributions are severely non-normal (absolute skewness and kurtosis values below 3 and 10, respectively; Blunch, 2016). To evaluate model quality, we used the following indices: Comparative Fit Index (CFI), Satorra-Bentler $\chi^{2} /$ degrees of freedom (SB $\left.\chi^{2} / \mathrm{df}\right)$, Root Mean Square Error of Approximation (RMSEA), and Incremental Fit Index (IFI). The following criteria were considered for an adequate fit: $\mathrm{SB}^{2} / \mathrm{df}<5$, CFI and IFI $>.90$, RMSEA <.08; and for a good fit: $\mathrm{SB} \chi^{2} / \mathrm{df}<2$, CFI and IFI $>.95$, RMSEA $<.06$ (Blunch, 2016; West et al., 2012). The online sample size calculator for structural equation models (https://www.danielsoper.com/statcalc/calculator. aspx?id=89) was used to calculate the sample size required considering a medium effect size of .04, a statistical power level of .08 , and a probability level of .001 . The calculator returned that the minimum sample size required to detect the specified effect, and the minimum sample size required given the structural complexity of our models would be lower than $N=130$. Our models did not include the potential influence of covariates (e.g., individual, family and community variables) because the participants selection criterion aimed at homogenous participants (e.g., in terms of age, reading ability). Pearson correlations were considered high if above .50, low if below .20, and moderate if between .20 and .50 (Ferguson, 2009). The reliability coefficient Alpha ( $\alpha$ ) was considered adequate if above .70, good if above .80 (Field, 2013). 
Table 1. Correlations and descriptive statistics for our study variables.

\begin{tabular}{|c|c|c|c|c|c|c|c|}
\hline & 1 & 2 & 3 & 4 & 5 & 6 & 7 \\
\hline 1. Machiavellianism & - & & & & & & \\
\hline 2. Psychopathy & $.71^{* * *}$ & - & & & & & \\
\hline 3. Narcissism & $.60^{* * *}$ & $.54^{* * *}$ & - & & & & \\
\hline 4. Brief self-control scale & $.68^{* * *}$ & $.78^{* * *}$ & $.45^{* * *}$ & - & & & \\
\hline $\begin{array}{l}\text { 5. Self-reported } \\
\text { delinquency }\end{array}$ & $.61^{* * *}$ & $.77^{* * *}$ & $.50^{* * *}$ & $.68^{* * *}$ & - & & \\
\hline $\begin{array}{l}\text { 6. Conduct disorder } \\
\text { screener }\end{array}$ & $.64^{* * *}$ & $.77^{* * *}$ & $.52^{* * *}$ & $.70^{* * *}$ & $.82^{* * *}$ & - & \\
\hline 7. Crime seriousness & $.64^{* * *}$ & $.72^{* * *}$ & $.53^{* * *}$ & $.68 * * *$ & $.82^{* * *}$ & $.83^{* * *}$ & - \\
\hline $\begin{array}{l}\text { Mean (Standard } \\
\text { Deviation) }\end{array}$ & $\begin{array}{l}8.18 \\
(2.64)\end{array}$ & $\begin{array}{l}7.60 \\
(3.34)\end{array}$ & $\begin{array}{l}11.66 \\
(3.10)\end{array}$ & $\begin{array}{c}46.62 \\
(7.69)\end{array}$ & $\begin{array}{l}3.30 \\
(5.64)\end{array}$ & $\begin{array}{l}8.88 \\
(2.38)\end{array}$ & $\begin{array}{l}0.88 \\
(1.18)\end{array}$ \\
\hline Skewness & .44 & 1.08 & -.03 & .46 & 2.59 & 1.06 & 1.02 \\
\hline Kurtosis & -.56 & .21 & -.79 & -.28 & 7.07 & .84 & -.13 \\
\hline
\end{tabular}

\section{Results}

Table 1 presents the correlations among our study variables along with descriptive statistics. All the traits were strongly positively correlated (rs range from .45 to .83). The psychopathy factor of the Dirty Dozen presented the highest correlations with self-reported delinquency and CD, as well as with self-control.

Figure 1 displays the first model. This model presented an adequate fit: $\mathrm{SB}^{2} / \mathrm{df}=648.61 / 160, \mathrm{CFI}=.93$, IFI $=.93$, RMSEA $=.07$ [.07-.08]. Psychopathy had a positive impact on low self-control $(\beta=.68, p \leq .001)$, which in turn impacted self-reported delinquency $(\beta=.15, p \leq .05)$. The total effect of psychopathy on self-reported delinquency $(\beta=.65, p \leq .001)$ included both the indirect effect via self-control $(\beta=.11, p \leq .05)$ and the direct effect on self-reported delinquency $(\beta=.55, p \leq .001)$. The total, direct and indirect effects of psychopathy on self-reported delinquency were significant. Furthermore, $16.92 \%(.11 / .65=.1692)$ of the total effect of psychopathy on self-reported delinquency was explained by the tendency of youth with higher psychopathic dark traits to report higher levels of self-control deficits.

Machiavellianism had a positive impact on low self-control $(\beta=.30$, $p \leq .001)$, which in turn impacted self-reported delinquency $(\beta=.15$, $p \leq .05)$. The total effect of Machiavellianism on self-reported delinquency $(\beta=.16, p \leq .05)$ included both the indirect effect via self-control $(\beta=.05$, $p \leq .05)$ and the direct effect on self-reported delinquency $(\beta=.11, n s)$. That is, the total and indirect effects of Machiavellianism on self-reported delinquency were significant, but the direct effect was not. Furthermore, 31.25\% (.05/ $.16=.3125)$ of the total effect of Machiavellianism on self-reported delinquency was explained by the tendency of youth with higher Machiavellian dark traits to report higher levels of self-control deficits.

Narcissism had a negative impact on low self-control $(\beta=-.09, p \leq .05)$, which in turn impacted self-reported delinquency $(\beta=.15, p \leq .05)$. The total effect of narcissism on self-reported delinquency $(\beta=.06, n s)$ included 


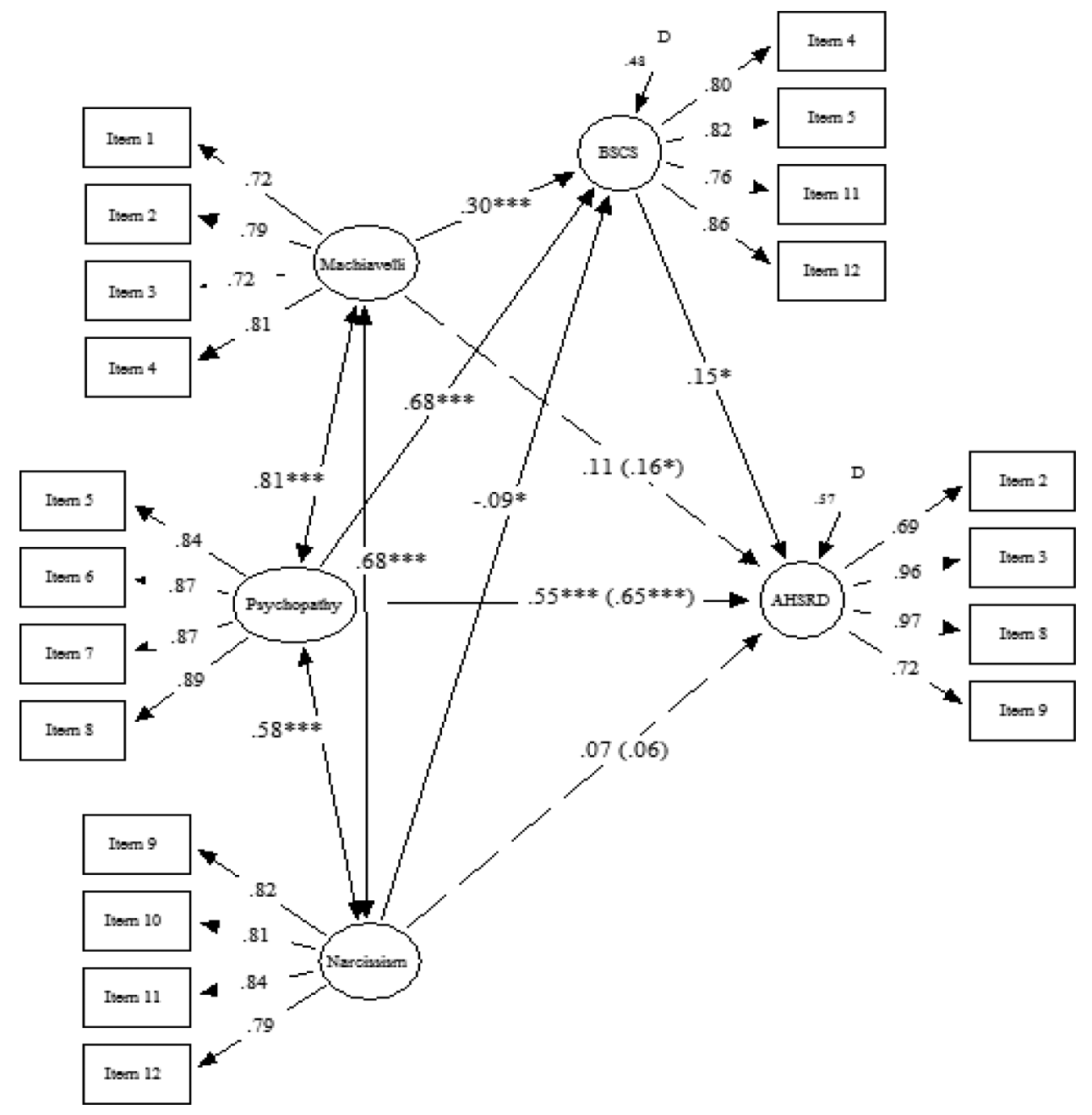

Figure 1. Effects of Dark Triad on delinquency mediated by low self-control. Machiavelli $=$ Machiavellianism; BSCS $=$ Brief Self-Control Scale; AHSRD = Add Health SelfReport Delinquency; Total effects are included in parentheses; ${ }^{*} p \leq .05,{ }^{* *} p \leq .01,{ }^{* * *} p \leq .001$.

both the indirect effect via self-control $(\beta=-.02, n s)$ and the direct effect on self-reported delinquency $(\beta=.07, n s)$. That is, the total, direct and indirect effects of narcissism on self-reported delinquency were all nonsignificant.

Figure 2 shows the second model. This model also had an adequate fit $\left(\mathrm{SB} \chi^{2} / \mathrm{df}=621.92 / 160, \mathrm{CFI}=.93\right.$, IFI $=.93$, RMSEA $\left.=.07[.07-.08]\right)$. Psychopathy had a positive impact on low self-control $(\beta=.68, p \leq .001)$, which in turn impacted $\mathrm{CD}(\beta=.21, p \leq .01)$. The total effect of psychopathy on $\mathrm{CD}(\beta=.67, p \leq .001)$ included both the indirect effect via self-control $(\beta=.14, p \leq .01)$ and the direct effect on $\operatorname{CD}(\beta=.53, p \leq .001)$. The total, direct and indirect effects of psychopathy on CD were significant. Moreover, 20.89\% 
$(.14 / .67=.2089)$ of the total effect of psychopathy on CD was explained by the tendency of youth with higher psychopathic dark traits to report higher levels of self-control deficits.

Machiavellianism had a positive impact on low self-control $(\beta=.30$, $p \leq .001)$, which in turn impacted $\operatorname{CD}(\beta=.21, p \leq .05)$. The total effect of Machiavellianism on $\operatorname{CD}(\beta=.21, p \leq .05)$ which included both the indirect effect via self-control $(\beta=.06, p \leq .05)$ and the direct effect on $\operatorname{CD}(\beta=.15$, $p \leq .05)$. That is, the total, direct and indirect effects of $\mathrm{p}$ Machiavellianism on CD were significant. Moreover, $28.57 \%(.06 / .21=.2857)$ of the total effect of Machiavellianism on CD was explained by the tendency of youth with higher Machiavellian dark traits to report higher levels of self-control deficits.

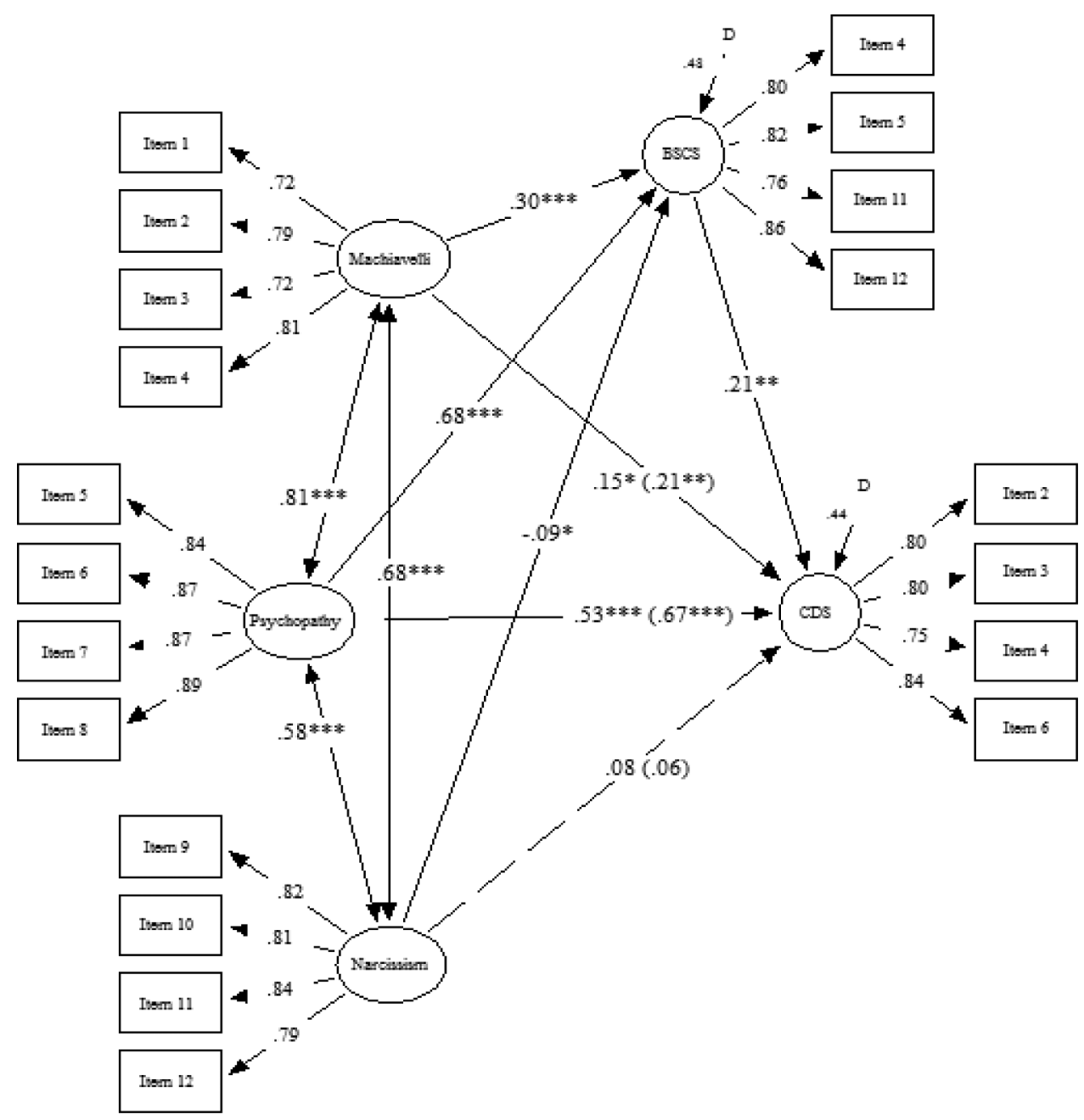

Figure 2. Effects of Dark Triad on CD mediated by low self-control. Machiavelli = Machiavellianism; BSCS = Brief Self-Control Scale; CDS = Conduct Disorder Screener; Total effects are included in parentheses; ${ }^{*} p \leq .05,{ }^{* *} p \leq .01,{ }^{* *} p \leq .001$. 
Narcissism had a negative impact on low self-control $(\beta=-.09, p \leq .05)$, which in turn impacted $\mathrm{CD}(\beta=.21, p \leq .01)$. The total effect of narcissism on $\mathrm{CD}(\beta=.06, n s)$ included both the indirect effect via self-control $(\beta=-.02, n s)$ and the direct effect on $\operatorname{CD}(\beta=.08, n s)$. That is, the total, direct and indirect effects of narcissism on $\mathrm{CD}$ were all non-significant.

Finally, Figure 3 shows the third model. This model also had an adequate fit $\left(\mathrm{SB} \chi^{2} / \mathrm{df}=530.75 / 110, \mathrm{CFI}=.93\right.$, IFI $=.93$, RMSEA $\left.=.08[.07-.09]\right)$. Psychopathy had a positive impact on low self-control $(\beta=.68, p \leq .001)$, which in turn impacted crime seriousness $(\beta=.19, p \leq .01)$. The total effect of psychopathy on crime seriousness $(\beta=.53, p \leq .001)$ included both the indirect effect via self-control $(\beta=.13, p \leq .01)$ and the direct effect on crime seriousness $(\beta=.40, p \leq .001)$. The total, direct and indirect effects of psychopathy on crime seriousness were significant. Moreover, $24.52 \%(.13 / .53=.2452)$ of the total effect of psychopathy on crime seriousness was explained by the tendency of youth with higher psychopathic dark traits to report higher levels of selfcontrol deficits.

Machiavellianism had a positive impact on low self-control $(\beta=.30$, $p \leq .001)$, which in turn impacted crime seriousness $(\beta=.19, p \leq .01)$. The total effect of Machiavellianism on crime seriousness $(\beta=.21, p \leq .01)$ which included both the indirect effect via self-control $(\beta=.06, p \leq .05)$ and the direct effect on crime seriousness $(\beta=.15, p \leq .05)$. That is, the total, direct and indirect effects of Machiavellianism on crime seriousness were significant. Moreover, $28.57 \%(.06 / .21=.2857)$ of the total effect of Machiavellianism on crime seriousness was explained by the tendency of youth with higher Machiavellian dark traits to report higher levels of selfcontrol deficits.

Narcissism had a negative impact on low self-control $(\beta=-.09, p \leq .05)$, which in turn impacted crime seriousness $(\beta=.19, p \leq .01)$. The total effect of narcissism on crime seriousness $(\beta=.10, p \leq .05)$ included both the indirect effect via self-control $(\beta=-.02, n s)$ and the direct effect on crime seriousness $(\beta=.12, p \leq .05)$. That is, the total and direct effects of narcissism on crime seriousness were significant, but not the indirect effect. It is important to mention that the effects reported in these three mediation models take into consideration the fact that the Dark Triad traits are positively and significantly correlated $(p \leq .001)$.

\section{Discussion}

There is little question that individuals whose personality functioning is selfcentered and geared toward self-interest at the expense of others, who are calculating, duplicitous, and exploitative, and who exhibit emotional and behavioral regulation deficits are at greater risk for broadband conduct problems. The dark features inherent to the Dark Triad and low self- 


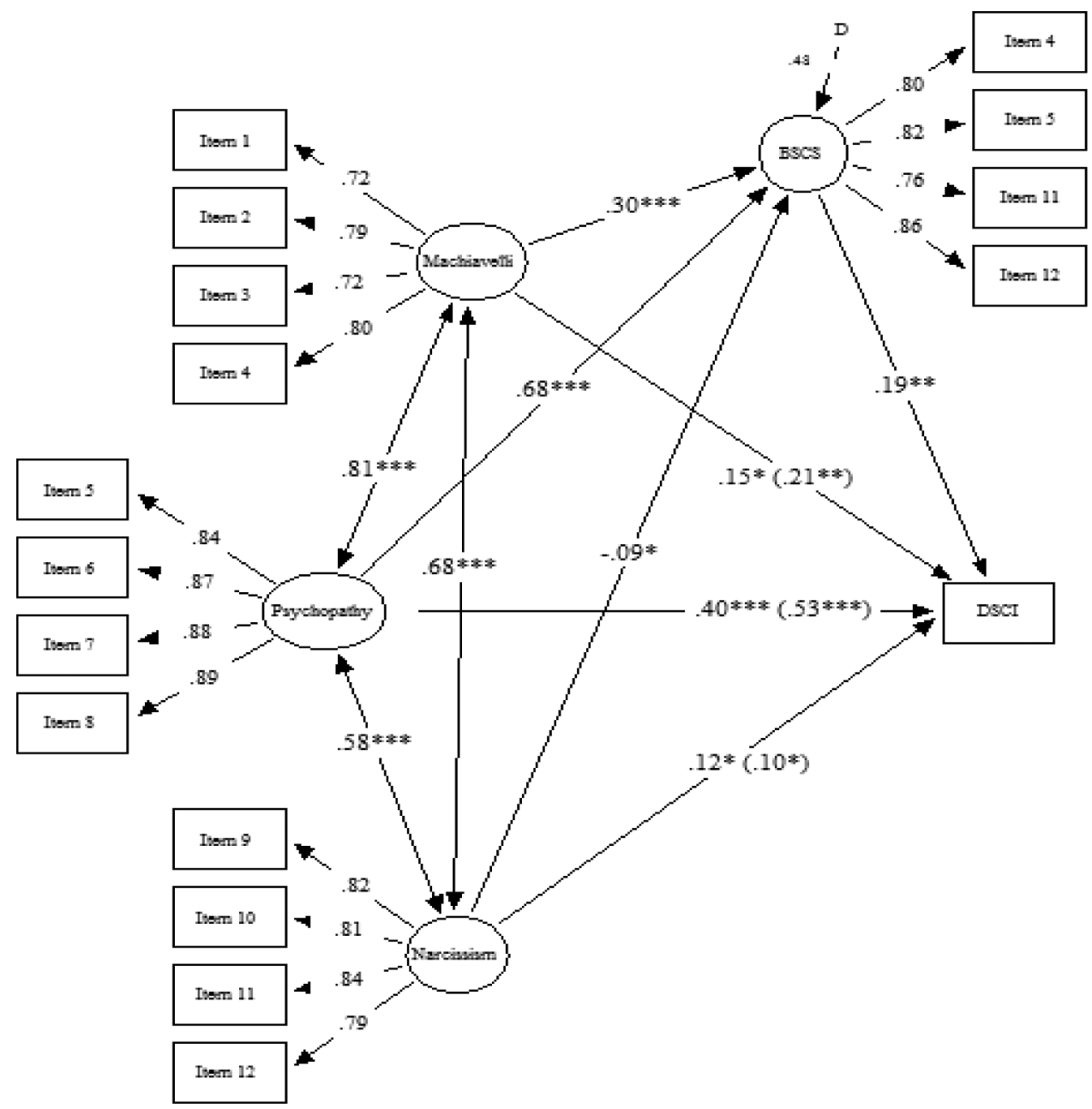

Figure 3. Effects of Dark Triad on crime seriousness mediated by low self-control. Machiavelli $=$ Machiavellianism; BSCS $=$ Brief Self-Control Scale; DSCI $=$ Delinquency Seriousness Classification Index; Total effects are included in parentheses; ${ }^{*} p \leq .05,{ }^{* *} p \leq .01,{ }^{* * *} p \leq .001$.

control are consistently linked to conduct problems. However, there are also significant concerns about the Dark Triad on statistical and conceptual grounds especially relating to its distinctness (Miller et al., 2019; Muris et al., 2017; Sleep et al., 2017), its poor convergent validity with other psychopathy measures (Maples et al., 2014), and whether the assortment of dark traits is redundant to psychopathy (Miller et al., 2017, 2019). Indeed, as a stand-alone construct, psychopathy is a condition that includes narcissism and the calculating manipulation seen in Machiavellianism thus conceptually perhaps there is little reason to encumber psychopathy with these additional dark traits. Indeed, the current analyses show that psychopathy clearly presented the highest impact in terms of links to low self-control and juvenile delinquency, conduct disorder, and crime seriousness. This is 
consistent with the reputation of psychopathy as one of the most important drivers of delinquency and related conduct (Baglivio, 2019; Baglivio et al., 2020; DeLisi, 2016; Hare, 1999; Pechorro et al., 2019; Ray et al., 2020; Virtanen et al., 2020).

Our findings also indicate that low self-control partially mediated the association between both psychopathy and Machiavellianism and the behavioral outcomes. Machiavellianism mostly did as well albeit to a lesser degree. Specifically, self-control mediated approximately $17 \%$ of the effect of psychopathy on self-reported delinquency, nearly $21 \%$ of the effect of psychopathy on Conduct Disorder, and nearly $25 \%$ of the effect of psychopathy on crime seriousness. Irrespective of the unique predictive validity of psychopathy for understanding antisocial outcomes, self-control also plays a non-trivial role at mediating those effects. This evidence of the mutual significance of psychopathy and self-control to conduct problems and the mediation by self-control is consistent with recent dialogue in criminology where the relative merits of self-control and psychopathy as general theories are under evaluation (cf., Altikriti et al., 2020; Armstrong et al., 2020; DeLisi et al., 2018; Flexon et al., 2016; Wright et al., 2017).

On the other hand, narcissism presented little or no direct significant effect on the examined outcomes, and even presented negative associations with low self-control. Additionally, narcissism was not mediated by low selfcontrol either in part or fully. This is consistent with previous studies suggesting that narcissism may be better understood as secondary in terms of the psychopathy construct conceptualization. For example, Vize et al.'s (2018) meta-analytic findings showed that the nomological networks of psychopathy and Machiavellianism strongly overlap, while narcissism presented substantial differential relations when compared with psychopathy and Machiavellianism.

We acknowledge some limitations to the study that help contextualize the findings. We recognize that student samples such as the one used in the present study contain individuals whose behavioral functioning is normative (DeLisi, 2013; Moffitt, 1993, 2018) and whose global psychopathology including personality pathology is low compared to detained and institutionalized delinquents (e.g., Farina et al., 2018; Pechorro et al., 2019; Trulson et al., 2016; Washburn et al., 2007). Although there is certainly adequate variation in these constructs in these data to execute analyses, the generally benign nature of the sample is a shortcoming and we invite replication with adjudicated and clinical samples to see if the current findings hold. Additionally, the current estimates are likely inflated by shared methods variance as youth self-reported all outcomes. The study is also limited in that we did not control statistically for the potential influence of covariates (e.g., individual, family and community variables) that could add robustness to the path analyses models. On the other hand, it is important to mention that a strength of the present study is that it 
adds to the literature by using structural equation models to examine the data that offer more meaningful results in terms of validity, reliability and complex patterns of relationships analysis (Kline, 2016; Maroco, 2021).

Future research should employ arrest or conviction data to see how Dark Triad features relate to official indicators of antisocial behavior, and, whether and to what degree low self-control mediates those outcomes. As suggested by others (Miller et al., 2019; Muris et al., 2017), modeling the constitutive traits of the Dark Triad along with self-control across diverse data sources is needed to elucidate the dark features of human personality that most contribute to conduct problems, delinquency, and violence.

\section{Disclosure statement}

No potential conflict of interest was reported by the author(s).

\section{Funding}

This study was partially conducted at the Psychology Research Centre (CIPsi/UM PSI/01662) School of Psychology, University of Minho, and was partially funded by the Portuguese Foundation for Science and Technology (FCT) and the Portuguese Ministry of Science, Technology and Higher Education (UID/PSI/01662/2019) through the Portuguese State budget (UIDB/01662/2020).

\section{ORCID}

Pedro Pechorro PhD (D) http://orcid.org/0000-0003-3728-5380

João Maroco PhD (D) http://orcid.org/0000-0001-9214-5378

\section{Data availabilty}

Data is available from the first author upon reasonable request.

\section{References}

Altikriti, S., Theocharidou, K., \& Sullivan, C. J. (2020). Specific theories of crime? A longitudinal assessment of the competing effects of psychopathy and self-control. Journal of Crime and Justice, 43(5), 547-567. https://doi.org/10.1080/0735648X.2020. 1727765

Armstrong, T. A., Boisvert, D., Wells, J., Lewis, R. H., Cooke, E., \& Woeckner, M. (2020). Assessing potential overlap between self-control and psychopathy: A consideration of the Grasmick self-control scale and the Levenson self-report psychopathy scale. Journal of Criminal Justice, 70, 101725. https://doi.org/10.1016/j.jcrimjus.2020.101725

Baglivio, M. T. (2019). Psychopathy among juvenile justice system-involved youth. In M. DeLisi (Ed.), Routledge international handbook of psychopathy and crime (pp. 579-597). Routledge. 
Baglivio, M. T., Wolff, K. T., DeLisi, M., \& Jackowski, K. (2020). The role of adverse childhood experiences (ACEs) and psychopathic features on juvenile offending criminal careers to age 18. Youth Violence and Juvenile Justice, 18(4), 337-364. https://doi.org/10.1177/ 1541204020927075

Bentler, P., \& Wu, E. (2018). Supplement to EQS 6.4 for Windows user's guide. Multivariate Software.

Blunch, N. (2016). Introduction to structural equation modeling using IBM SPSS statistics and EQS. SAGE.

De Ridder, D., Lensvelt-Mulders, G., Finkenauer, C., Stok, F. M., \& Baumeister, R. F. (2012). Taking stock of self-control: A meta-analysis of how trait self-control relates to a wide range of behaviors. Personality and Social Psychology Review, 16(1), 76-99. https://doi.org/10. $1177 / 1088868311418749$

DeLisi, M. (2013). The Moffittization of criminology. International Journal of Offender Therapy and Comparative Criminology, 57(8), 911-912. https://doi.org/10.1177/0306624X13493391

DeLisi, M. (2016). Psychopathy as unified theory of crime. Palgrave Macmillan.

DeLisi, M., Tostlebe, J., Burgason, K., Heirigs, M., \& Vaughn, M. (2018). Self-control versus psychopathy: A head-to-head test of general theories of antisociality. Youth Violence and Juvenile Justice, 16(1), 53-76. https://doi.org/10.1177/1541204016682998

Farina, A. S., Holzer, K. J., DeLisi, M., \& Vaughn, M. G. (2018). Childhood trauma and psychopathic features among juvenile offenders. International Journal of Offender Therapy and Comparative Criminology, 62(14), 4359-4380. https://doi.org/10.1177/ $0306624 X 18766491$

Ferguson, C. (2009). An effect size primer: A guide for clinicians and researchers. Professional Psychology, Research and Practice, 40(5), 532-538. https://doi.org/10.1037/ a0015808

Field, A. (2013). Discovering statistics using IBM SPSS statistics (4th ed.). SAGE.

Flexon, J. L., Meldrum, R. C., Young, J. T., \& Lehmann, P. S. (2016). Low self-control and the Dark Triad: Disentangling the predictive power of personality traits on young adult substance use, offending and victimization. Journal of Criminal Justice, 46, 159-169. https://doi. org/10.1016/j.jcrimjus.2016.05.006

Gottfredson, M. R., \& Hirschi, T. (1990). A general theory of crime. Stanford University Press.

Hare, R. D. (1999). Without conscience: The disturbing world of the psychopaths among us. The Guilford Press.

Jonason, P. K., \& Tost, J. (2010). I just cannot control myself: The Dark Triad and self-control. Personality and Individual Differences, 49(6), 611-615. https://doi.org/10.1016/j.paid.2010. 05.031

Jonason, P. K., \& Webster, G. D. (2010). The dirty dozen: A concise measure of the dark triad. Psychological Assessment, 22(2), 420-432. https://doi.org/10.1037/a0019265

Kline, R. B. (2016). Principles and practice of structural equation modeling (4th ed.). The Guilford Press.

Larson, M., Vaughn, M. G., Salas-Wright, C. P., \& DeLisi, M. (2015). Narcissism, low self-control, and violence among a nationally representative sample. Criminal Justice and Behavior, 42(6), 644-661. https://doi.org/10.1177/0093854814553097

Lewinsohn, P. M., Rohde, P., \& Farrington, D. P. (2000). The OADP-CDS: A brief screener for adolescent conduct disorder. Journal of the American Academy of Child and Adolescent Psychiatry, 39(7), 888-895. https://doi.org/10.1097/000004583-2000007000-00018

Loeber, R., Farrington, D. P., Stouthamer-Loeber, M., \& Van Kammen, W. B. (1998). Antisocial behavior and mental health problems. Erlbaum.

Lyons, M., \& Jonason, P. K. (2015). Dark triad, tramps, and thieves. Journal of Individual Differences, 36(4), 215-220. https://doi.org/10.1027/1614-0001/a000177 
Maples, J. L., Lamkin, J., \& Miller, J. D. (2014). A test of two brief measures of the dark triad: The dirty dozen and short dark triad. Psychological Assessment, 26(1), 326-331. https://doi. org/10.1037/a0035084

Maroco, J. (2021). Análise de equações estruturais [Structural equations analysis] (3rd ed.). ReportNumber Ltd.

Miller, J. D., Hyatt, C. S., Maples-Keller, J. L., Carter, N. T., \& Lynam, D. R. (2017). Psychopathy and Machiavellianism: A distinction without a difference? Journal of Personality, 85(4), 439-453. https://doi.org/10.1111/jopy.12251

Miller, J. D., Vize, C., Crowe, M. L., \& Lynam, D. R. (2019). A critical appraisal of the dark-triad literature and suggestions for moving forward. Current Directions in Psychological Science, 28(4), 353-360. https://doi.org/10.1177/0963721419838233

Moffitt, T. E. (1993). Adolescence-limited and life-course-persistent antisocial behavior: A developmental taxonomy. Psychological Review, 100(4), 674-701. https://doi.org/10. 1037/0033-295X.100.4.674

Moffitt, T. E. (2018). Male antisocial behaviour in adolescence and beyond. Nature Human Behaviour, 2(3), 177-186. https://doi.org/10.1038/s41562-018-0309-4

Mowlaie, M., Abolghasemi, A., \& Aghababaei, N. (2016). Pathological narcissism, brain behavioral systems and tendency to substance abuse: The mediating role of self-control. Personality and Individual Differences, 88, 247-250. https://doi.org/10.1016/j.paid.2015. 09.019

Muris, P., Merckelbach, H., Otgaar, H., \& Meijer, E. (2017). The malevolent side of human nature: A meta-analysis and critical review of the literature on the dark triad (narcissism, Machiavellianism, and psychopathy). Perspectives on Psychological Science, 12(2), 183-204. https://doi.org/10.1177/1745691616666070

O’Boyle, E. H., Forsyth, D. R., Banks, G. C., Story, P. A., \& White, C. D. (2015). A meta-analytic test of redundancy and relative importance of the dark triad and five-factor model of personality. Journal of Personality, 83(6), 644-664. https://doi.org/10.1111/jopy.12126

Palma, V., Pechorro, P., Jesus, S., \& Nunes, C. (in press). Psychometric properties of the conduct disorder screener among Portuguese youths.

Paulhus, D. L., \& Williams, K. M. (2002). The dark triad of personality: Narcissism, Machiavellianism, and psychopathy. Journal of Research in Personality, 36(6), 556-563. https://doi.org/10.1016/S0092-6566(02)00505-6

Pechorro, P., DeLisi, M., Gonçalves, R., Quintas, J., \& Palma, V. (2021). The brief self-control scale and its refined version among incarcerated and community youths: Psychometrics and measurement invariance. Deviant Behavior, 42(3), 425-442. https://doi.org/10.1080/ 01639625.2019.1684942

Pechorro, P., Jonason, P. K., Raposo, V., \& Maroco, J. (2021). Dirty dozen: A concise measure of dark triad traits among at-risk youths. Current Psychology, 40(7), 3522-3531. https://doi. org/10.1007/s12144-019-00288-9

Pechorro, P., Moreira, K., Basto-Pereira, M., Oliveira, J. P., \& Ray, J. V. (2019). The self-report delinquency scale from the national longitudinal study of adolescent to adult health among at-risk for delinquency youths. Violence and Victims, 34(1), 120-135. https://doi.org/10. 1891/0886-6708.VV-D-17-00165

Pechorro, P., Seto, M. C., Ray, J. V., Alberto, I., \& Simões, M. R. (2019). A prospective study on self-reported psychopathy and criminal recidivism among incarcerated male juvenile offenders. International Journal of Offender Therapy and Comparative Criminology, 63 (14), 2383-2405. https://doi.org/10.1177/0306624X19849569

Pratt, T. C., Turanovic, J. J., Fox, K. A., \& Wright, K. A. (2014). Self-control and victimization: A meta-analysis. Criminology, 52(1), 87-116. https://doi.org/10.1111/1745-9125. 12030 
Ray, J. V., Baker, T., \& Caudy, M. S. (2020). Revisiting the generality of rational choice theory: Evidence for general patterns but differential effects across varying levels of psychopathy. Journal of Criminal Justice, 66, 101654. https://doi.org/10.1016/j.jcrimjus.2019.101654

Schreiber, A., \& Marcus, B. (2020). The place of the "dark triad" in general models of personality: Some meta-analytic clarification. Psychological Bulletin, 146(11), 1021-1041. https://doi.org/10.1037/bul0000299

Sekhar, S., Uppal, N., \& Shukla, A. (2020). Dispositional greed and its dark allies: An investigation among prospective managers. Personality and Individual Differences, 162, 110005. https://doi.org/10.1016/j.avb.2020.110005

Sleep, C. E., Lynam, D. R., Hyatt, C. S., \& Miller, J. D. (2017). Perils of partialing redux: The case of the Dark Triad. Journal of Abnormal Psychology, 126(7), 939-950. https://doi.org/10. 1037/abn0000278

Tangney, J. P., Baumeister, R. F., \& Boone, A. L. (2004). High self-control predicts good adjustment, less pathology, better grades, and interpersonal success. Journal of Personality, 72(2), 271-324. https://doi.org/10.1111/j.0022-3506.2004.00263.x

Trahair, C., Baran, L., Flakus, M., Kowalski, C. M., \& Rogoza, R. (2020). The structure of the Dark Triad traits: A network analysis. Personality and Individual Differences, 167, 110265. https://doi.org/10.1016/j.avb.2020.110265

Truhan, T. E., Wilson, P., Mõttus, R., \& Papageorgiou, K. A. (2021). The many faces of dark personalities: An examination of the Dark Triad structure using psychometric network analysis. Personality and Individual Differences, 171, 110502. https://doi.org/10.1016/j.avb. 2020.110502

Trulson, C. R., Haerle, D. R., Caudill, J. W., \& DeLisi, M. (2016). Lost causes: Blended sentencing, second chances, and the Texas youth commission. University of Texas Press.

Vaughn, M. G., DeLisi, M., Beaver, K. M., Wright, J. P., \& Howard, M. O. (2007). Toward a psychopathology of self-control theory: The importance of narcissistic traits. Behavioral Sciences \& the Law, 25(6), 803-821. https://doi.org/10.1002/bsl.789

Vaughn, M. G., Newhill, C. E., DeLisi, M., Beaver, K. M., \& Howard, M. O. (2008). An investigation of psychopathic features among delinquent girls: Violence, theft, and drug abuse. Youth Violence and Juvenile Justice, 6(3), 240-255. https://doi.org/10.1177/ 1541204007312298

Vazsonyi, A. T., Mikuška, J., \& Kelley, E. L. (2017). It's time: A meta-analysis on the self-control -deviance link. Journal of Criminal Justice, 48, 48-63. https://doi.org/10.1016/j.jcrimjus. 2016.10.001

Virtanen, S., Latvala, A., Andershed, H., Lichtenstein, P., Tuvblad, C., Colins, O. F., Suvisaari, J., Larsson, H., \& Lundström, S. (2020). Do psychopathic personality traits in childhood predict subsequent criminality and psychiatric outcomes over and above childhood behavioral problems? Journal of Criminal Justice, 101761. https://doi.org/10.1016/j. jcrimjus.2020.101761

Vize, C. E., Collison, K. L., Miller, J. D., \& Lynam, D. R. (2020). The "core" of the dark triad: A test of competing hypotheses. Personality Disorders: Theory, Research, and Treatment, 11 (2), 91-99. https://doi.org/10.1037/per0000386

Vize, C. E., Lynam, D. R., Collison, K. L., \& Miller, J. D. (2018). Differences among dark triad components: A meta-analytic investigation. Personality Disorders: Theory, Research, and Treatment, 9(2), 101-111. https://doi.org/10.1037/per0000222

Vize, C. E., Miller, J. D., \& Lynam, D. R. (2019). Antagonism in the dark triad. In J. D. Miller \& D. R. Lynam (Eds.), The handbook of antagonism (pp. 253-267). Academic Press.

Walters, G. D. (2016). Are behavioral measures of self-control and the Grasmick self-control scale measuring the same construct? A meta-analysis. American Journal of Criminal Justice, 41(2), 151-167. https://doi.org/10.1007/s12103-015-9317-3 
Walters, G. D. (2019). Early attachment and narcissistic entitlement: Tracing the roots of adolescent proactive criminal thinking. Journal of Developmental and Life-Course Criminology, 5(2), 266-285. https://doi.org/10.1007/s40865-019-00117-4

Washburn, J. J., Romero, E. G., Welty, L. J., Abram, K. M., Teplin, L. A., McClelland, G. M., \& Paskar, L. D. (2007). Development of antisocial personality disorder in detained youths: The predictive value of mental disorders. Journal of Consulting and Clinical Psychology, 75(2), 221-231. https://doi.org/10.1037/0022-006X.75.2.221

West, S. G., Taylor, A. B., \& Wu, W. (2012). Model fit and model selection in structural equation modeling. In R. H. Hoyle (Ed.), Handbook of structural equation modeling (pp. 209-231). The Guilford Press.

Wright, J., Morgan, M., Almeida, P., Almosaed, N., Moghrabi, S., \& Bashatah, F. (2017). Malevolent forces: Self-control, the Dark Triad, and crime. Youth Violence and Juvenile Justice, 15(2), 191-215. https://doi.org/10.1177/1541204016667995 